\title{
Qué y cómo se ve televisión \\ en México: oferta y consumo \\ en tres áreas metropolitanas ${ }^{1}$
}

Juan Enrique Huerta Wong
Aída Cerda Cristerna ${ }^{2}$

Los datos difieren poco al hablar de la abrumadora presencia de la televisión en la vida cotidiana. En México, más de $80 \%$ de personas reportan verla a diario (Séptima entrega de consumo cultural, 2001). En 1998, había 18 millones de telehogares, con 1.2 televisores por hogar en promedio; en cada casa, la televisión permanecía encendida siete horas y media durante el día (TV Azteca, 1999). Hay, al menos, 97 millones de hogares conectados a la televisión (Jara Elías, 1997), de los que 4 millones, oficialmente, cuentan con televisión privada (Huerta, 1999) -cable, satélite, etcétera-y 6 millones, con videocasetera (INEGI, 1996). De todos, la gran mayoría cuenta con un control remoto (Datos de IBOPE, 1996). En Monterrey, dos terceras partes de la población ven más de 4 horas de televisión diariamente (Huerta Wong, 1999).

El fenómeno se extiende por muchas partes del mundo. Muchas personas en muchos países rigen sus tiempos de trabajo, información y esparcimiento influidos en mayor o menor medida por el tiempo dedicado a la televisión (Silverstone, 1996). El espacio doméstico también está dispuesto frecuentemente para realizar esta actividad y las charlas que sostenemos diariamente suelen derivar de programas televisivos (Barrios, 1992; Covarrubias, 1998). Aun la televisión influye en mayor o menor medida en las agendas públicas de una ciudad, país o región; ha modificado drásticamente, por ejemplo, la forma

1. Una versión preliminar de este texto fue presentada como ponencia en la III Bienal Iberoamericana de Comunicación: Globalización, Tecnología y Culturas. Universidad de las Américas, Cholula, Puebla, 8 a 10 de noviembre de 2001. Otra versión preliminar de este trabajo ganó el Certamen Juvenil de Ciencia y Tecnología de Nuevo León 2001, en la categoría de Ciencias Sociales.

2. ITESM, campus Monterrey, correo electrónico: jehuerta@itesm.mx. 
en que se concibe a eventos tan trascendentes en la cotidianidad como la Navidad, el Día de la Virgen de Guadalupe o, incluso, la Copa Mundial de futbol (Silverstone, 1996). Pero la importancia de la televisión pasa por alto precisamente debido a su integración en la vida cotidiana. Es tan cercana que los argumentos en torno a ella se vuelven obvios. En México, a pesar de los esfuerzos - cada vez mayores- que desde diversas perspectivas teóricas y metodológicas se han realizado, aún es incipiente el conocimiento que se tiene acerca del fenómeno.

Importante para conocer más acerca de este fenómeno cotidiano, la investigación acerca de la televisión ha de hacerse desde cuatro partes del proceso de oferta y consumo de contenido televisivo y puede realizarse de manera aislada o estudiando las complejas relaciones entre cada una de las partes del proceso. Estas partes son: producción, oferta, consumo y apropiación (Lozano, 1995-1996). La investigación aquí reportada sólo estudió la oferta y el consumo de contenido televisivo durante 1999 en las áreas metropolitanas de Ciudad de México, Guadalajara y Monterrey.

\section{Oferta}

¿Qué se ve en la televisión mexicana? Es una pregunta para la que aquí se reporta un tipo de respuesta a partir de evidencia recopilada longitudinalmente. En la charla cotidiana, el valor de la definición de lo que se ve en televisión es la categoría de calidad. En la discusión internacional del tema, se suele définir a la calidad como la diversidad de contenidos ofrecidos a la audiencia en un día y hora determinados (McQuail, 1998). Omnipresente en la vida cotidiana, la televisión ha de cumplir un servicio público. Este servicio consiste en satisfacer el interés público; de acuerdo con la Comisión Federal de Comunicaciones de Estados Unidos de Norteamérica, por interés público podemos entender aquello que pretende abarcar los intereses de todo el público y no sólo a cierto sector, así sea mayoritario. Como los intereses de la sociedad son diversos, se ha entendido que la categoría para medir la función pública de la televisión es la diversidad (Gutiérrez Gea, 2000).

En México, después de la fusión en 1973 de Telesistema Mexicano y Televisión Independiente de México, Televisa đominó el mercado televisivo comercial mexicano hasta 1993, cuando la administración federal privatizó los canales estatales de Imevisión (fundados en 1983), dando pie al surgimiento de Televisión Azteca. Con el surgimiento de la nueva cadena, los defensores de la privatización auguraron mayor diversidad. La competencia beneficiaría principalmente al público, pues habría otro tipo de programas y se proporcionaría acceso a otro tipo de actores sociales. A seis años de ese cambio (pues 
los datos fueron levantados en 1999), parecía necesario realizar un diagnóstico que permita evaluar el grado de diversidad ${ }^{3}$ y de servicio público que están ofreciendo ambas cadenas al auditorio televisivo nacional. Mediante un análisis de la programación de cuatro semanas de 1999 (una para cada trimestre del año), de los cuatro principales canales abiertos 4 nacionales de ambas empresas (canal 2, canal 5, canal 7 y canal 13), el presente trabajo ofrece evidencias sobre la diversidad que mostró la televisión abierta mexicana durante ese año, mediante la medición de la procedencia, formato y tipo de sus contenidos.

\section{Consumo}

Todos vemos televisión, pero icon cuánta atención y con qué grado de involucramiento, qué tipos de programas, en qué momentos? (Morley y Silverstone, 1994: 69). Y más aún: ¿qué características individuales o sociales influyen para modelar nuestras prácticas de exposición? Más allá de lo que se ve en televisión está el contexto en el que se ve. Si se desea estudiar la exposición a la televisión en la vida cotidiana, es necesario recurrir al análisis de dicha actividad a la luz de categorías sociales que definan al hogar -el lugar para ver televisión por excelencia - respecto a la sociedad en que se encuentra. Por ejemplo, la exposición a la televisión puede verse mediada por el sexo de la persona, ya que las convenciones culturales para cada género son distintas y pueden ocasionar diferencias en los patrones de consumo. También el nivel socioeconómico puede tener consecuencias en el tamaño de la casa, que sería un componente que opera directamente para determinar en algún grado las prácticas de exposición (Morley, 1992: 169). Por lo tanto, en este

3. En este trabajo se hace una distinción entre programación y contenidos. Programación se refiere al conjunto de programas como unidades, mientras que por contenidos se entiende el interior de cada unidad narrativa llamada programa. La diversidad mide el grado de diferencia al interior de la carta programática; un análisis complementario sería el de variedad, o el grado de diferencia al interior de cada programa. La diversidad se mide en forma vertical y horizontal, es decir, la oportunidad que un receptor puede tener para captar diferentes programas en un mismo canal en diferentes horarios (vertical) y la oportunidad que puede tener para ver diferentes programas en un horario determinado (horizontal), según Ishikawa y Kim (1996).

4. Se entiende por canales abiertos aquellos que están disponibles para el televidente con sólo encender el televisor, en contraposición con los privados, para cuyo acceso es necesario pagar una cuota suscribiéndose a una empresa. Canales públicos son aquellos sin fines de lucro, casi siempre propiedad de alguna entidad gubernamental o ìnstitución educativa, con fines educativos o culturales, en contraposición con los comerciales, cuyo objetivo central es lucrar. Para fines de este estudio, sólo se consideraron los canales abiertos, pues serían éstos los que tendrían una lógica de servicio público. 
trabajo se plantea la necesidad de estudiar la exposición a la televisión en la vida cotidiana en nuestro país, tratando de ubicar a los miembros del hogar respecto a la sociedad en que éste se encuentra inserto, de acuerdo con los diversos modos de interacción que, presuntamente, distinguen a cada género y nivel socioeconómico.

Por supuesto, no hay que dejar de advertir que los televidentes están rodeados por muchos factores que contribuyen a determinar la manera en que usan los medios de comunicación, de los cuales solamente se analizarán dos fuentes de mediación: género y nivel socioeconómico. Esto deja muchas preguntas abiertas, pero sabemos que la integración de las variables género y nivel socioeconómico es una de las principales preocupaciones de los investigadores de estudios culturales (Press, 1991), razón por la que se han elegido tales categorías.

\section{Metodología}

Los datos que aquí se reportan provienen del Programa de Investigación Televisión y Vida Cotidiana. Dirigido por José Carlos Lozano Rendón, el programa consiste en diez proyectos de investigación dedicados a recopilar, analizar, diseminar y divulgar evidencia acerca de los procesos de producción, oferta, consumo y apropiación de contenidos televisivos en México. Los autores fungieron como investigadores asociados y coordinadores de proyecto, por lo que sólo son reportados dos de los diez proyectos del programa, ${ }^{5}$ si bien participaron en la producción de la mayoría de ellos.

\section{Oferta}

El diagnóstico de la oferta se valió de una muestra longitudinal, compuesta por cuatro semanas de programación ( 8 a 14 de febrero, 10 a 16 de mayo, 9 a 15 de agosto y 8 a 14 de noviembre). El criterio fue seleccionar la segunda semana del segundo mes de cada trimestre, es decir, se dividió el periodo de análisis (un año) en cuatro partes, y se escogieron las semanas justo enmedio, con el fin de eliminar lo más posible los sesgos.

El primer instrumento de trabajo fue la carta programática publicada en el periódico de circulación nacional Excélsior, publicada en su sección nacio-

5. Para el trabajo de campo relacionado con los proyectos del programa Televisión y Vida Cotidiana, el Tecnológico de Monterrey recibió, en 1999, fondos de la Cátedra Televisa. 
nal, de donde se codificó la información. No se realizó una segunda muestra; se censaron todas las semanas, codificando toda la programación de los canales que conforman el estudio, entre las 6 y las 23:59 horas. Se aplicaron pruebas piloto y de confiabilidad a la programación de la semana 12-18 de abril, contando con un manual y hoja de codificación de variables semiabiertas, tras lo cual se despejaron dudas acerca de los tipos programáticos y se cerraron las variables hasta hacerlas nominales, para integrar un manual y hoja de codificación finales.

La unidad de análisis fue el programa, y para fines operacionales se codificó el número de minutos que cada uno registró, de modo que el análisis está hecho a partir de los minutos de programación y no del número de programas que conforman la muestra. De este modo, la muestra final fue de 118 mil 925 minutos codificados. Las variables principales fueron canal, minutos, formatos, tipos, ${ }^{6}$ país de origen y horario de programación.

\section{Consumo}

El estudio del consumo utilizó como base encuestas por muestreo. Los cuestionarios fueron aplicados casa por casa por la Unidad de Estudios Estadísticos del Tecnológico de Monterrey, entre marzo y abril de 1999, en Guadalajara, México y Monterrey y sus zonas metropolitanas. ${ }^{7}$ En cada ciudad se tomaron como marco de muestreo los mapas del Instituto Nacional de Estadística, Geografía e Informática (INEGI) agrupados por AGEB (grupos de manzanas de diferentes tamaños, definidos por el INEGI), y se obtuvo un muestreo probabilístico por conglomerados. En cada casa seleccionada se entrevistaba a la persona mayor de 15 años que atendiera la puerta.

El tamaño de muestra (n) para cada ciudad ( 800 casos o más) es superior a dicha cantidad $y$, por lo tanto, es adecuado para hacer generalizaciones, ${ }^{8}$

6. La tipología es el índice a partir del cual se miden formatos y tipos de programas. Un tipo de programa es una película o una telenovela, mientras que un formato abarca tipos más o menos afines, por ejemplo, ficción o información (Hillve, 1999).

7. Esto significa que al hablar de Monterrey se incluye también a los habitantes de Apodaca, Escobedo, Guadalupe, San Nicolás de los Garza, San Pedro Garza García y Santa Catarina. Para México, la zona metropolitana incluye además las delegaciones Álvaro Obregón, Azcapotzalco, Benito Juárez, Coyoacán, Cuauhtémoc, Gustavo A. Madero, Iztacalco, Iztapalapa, Magdalena Contreras, Miguel Hidalgo, Tláhuac, Tlalpan, Venustiano Carranza y Xochimilco. Junto con Guadalajara se consideran Tlaquepaque, Tonalá y Zapopan. Sin embargo, en lo sucesivo, cada vez que se hable de estas áreas se mencionará solamente el nombre de la ciudad que las representa.

8. Un tamaño de muestra suficiente para una población infinita o mayor a 100,000 , como la de estas ciudades, es de 400 observaciones, de acuerdo con la fórmula $n=\left(z^{2} p q\right) / e^{2}=384$, donde $\mathrm{z}=1.96$ (para 95\% de confiabilidad), $\mathrm{p}=0.5, q=0.5$ (pues se desconoce la prob- 
además de ser suficiente para realizar comparaciones por variables como género y nivel socioeconómico (véase tabla 1 ). ${ }^{9}$

Antes de entrar al análisis de los resultados, quizá se pueda adelantar que un primer rasgo de los hallazgos es que los entrevistados dijeron tener alrededor de dos aparatos de televisión en la vivienda. En Monterrey hay 1.85 televisores por hogar en promedio $(n=986, \sigma=0.88)$; en México, la media es de $1.89(\mathrm{n}=802, \sigma=0.93)$, y Guadalajara tiene el número más alto de aparatos, con 2.01 por vivienda $(v=900, \sigma=1.07)$. Sin embargo, en los tres casos la desviación estándar $(\sigma)$ es considerable dado el valor de la media $(x)$; esto sucede porque la variación en la cantidad de televisores por casa es amplia, pues hay desde uno hasta ocho televisores funcionando en algunos hogares. Ocho de cada diez viviendas tienen televisión abierta como única opción disponible, y una quinta parte de la muestra dijo contar con algún sistema de televisión de paga (entre los cuales Cablevisión es el más mencionado). Esto significa que todos los entrevistados tienen por lo menos acceso a los canales abiertos de televisión nacional.

\section{Resultados}

\section{Oferta}

Dado que se han reportado ya aquí los datos desglosados por formato (Lozano Rendón y Huerta Wong, 2001), se hace hincapié en este documento en el desglose por tipo, que resulta más ilustrador, además. El tipo dominante en la televisión mexicana es "dibujos animados" (18\% del total). Como muestra (véase tabla 2), semana a semana fue el tipo más programado por la televisión mexicana. Este dato muestra las carencias de la tipología, aunque se ha discutido aquí que la carta programática es la primera herramienta de un diagnóstico longitudinal, de acuerdo con la literatura internacional del tema. Aunque "dibujos animados" fue codificado como un tipo del formato "infan-

abilidad de éxito o fracaso) y e $=0.05$ (para un error de $5 \%$ ). Por lo tanto, las 986 encuestas levantadas en Monterrey, las 802 de México y las 900 de Guadalajara conforman una muestra estadísticamente válida. Ahora bien, si se desea conocer el margen de error específico que se tendría con estos tamaños de muestra, sólo es necesario despejar dicha variable en la fórmula, con lo cual obtendríamos que la muestra de Monterrey $(n=986)$ tiene un error de $3.12 \%$, la de México $(n=802)$ tiene un error de $3.46 \%$, y la de Guadalajara $(n=900)$ tiene un error de $3.26 \%$.

9. El nivel socioeconómico se categorizó de acuerdo con los criterios del INEGI, que se basan principalmente en el material de construcción y la apariencia de la casa, y después se validó con la colonia. Los codificadores hicieron la validación con ayuda de un mapa mercadológico de BIMSA. 
tiles", en realidad podría decirse que pertenece al formato "ficción". Cuatro de los 45 tipos codificados, "dibujos animados", "películas", "magazines" y "telenovelas" ocuparon más de $50 \%$ de toda la muestra.

Más que en el caso de los formatos, mostrados el año pasado, este conjunto de datos da a conocer la gran concentración existente en la oferta programática de la televisión abierta mexicana y la predominancia del formato ficción, pues sólo el tipo "magazine" no pertenece a este formato. Cabe mencionar que añadir un quinto tipo, noticiero, hace llegar la concentración a más de $60 \%$ y muestra la también importante bipolaridad ficción-información en que se encuentra dividida la oferta programática mexicana (Lozano Rendón y Huerta Wong, 2001). En general podemos señalar que los tipos televisivos transmitidos por televisión abierta en México durante 1999 mostraron alta concentración.

En cuanto a la diversidad vertical (véase tabla 3), se observa que el grado de concentración resulta mayor en los canales 2 y 5 de Televisa que en los de TV Azteca. El canal 7 de TV Azteca muestra grados menores de concentración y, aunque hay un énfasis en tipos como "ventas directas al público" (17\%), "dibujos animados" (15\%) y "películas" (11\%), su programación es incluso relativamente diversa en comparación con el canal 5 de Televisa. En este canal, sólo dos tipos de programación, "películas" (23.9\%) y "dibujos animados" (59\%), ocupan $79.4 \%$ de su programación. Aún restaría observar más detenidamente al contenido de las "películas", en los términos de variedad antes descritos, pues bien pudiera ser dirigido al público infantil. Tal concentración, particularmente en el caso de los programas dirigidos a la audiencia infantil, es preocupante, desde que se ha dado a conocer que los "dibujos animados" son los programas más violentos en la televisión mexicana (López Islas y Cerda Cristerna, 1999).

En Monterrey, los "programas cómicos mexicanos", las "películas" de Estados Unidos y de otros países, los programas de "aventuras" y de lo "insólito", los programas "culturales", los "deportes" y los "comentarios deportivos" son preferidos en mayor grado por el público masculino. Las mujeres dijeron ver "telenovelas" y programas "de chismes" con más frecuencia que los hombres.

Respecto a la diversidad horizontal, se ha mostrado también (Lozano Rendón y Huerta Wong, 2001) que ha sido baja, predominando la ficción en el horario AAA. Y como se ha visto, la descomposición de los datos por tipos radicaliza los resultados. Salvo en el horario A, en todos los casos (véase tabla 4) son tres los tipos que aglutinan más de $50 \%$ de la oferta programática: "noticieros" (11\%), "magazines" (22\%), "películas" (10\%) y "dibujos animados" (22\%), en el caso de la referida programación A; y “películas” (17\%, $20 \%)$, "telenovelas" $(17 \%, 21 \%)$ y "dibujos animados" $(23 \%, 8 \%)$ en el horario AA y en el AAA, respectivamente. 
Es interesante observar cómo los formatos "películas" y "telenovelas" muestran una clara tendencia al alza en tanto avanza el día. Particularmente llama la atención el crecimiento cotidiano de la presencia programática de las "telenovelas", y podemos recordar aquí que los datos desprendidos de la evidencia internacional (Kim, 1996; Ishikawa, 1996) sugieren que donde el drama es más importante, la diversidad es menor. Como en México no se tipifica al drama, por lo menos no en el lenguaje de los productores, la telenovela pudiera ser, por lo menos parcialmente, un testigo de que el fenómeno "a más drama menor diversidad", se repite aquí, aunque se acepta que esto es especulativo y que los datos no aportan mayor respaldo. Con todo, la evidencia parece suficiente para señalar que la diversidad horizontal es baja.

Los datos sugieren que existió escasa diversidad vertical tanto como horizontal. Si consideramos además la escasa diversidad en la estructura televisiva, podríamos coincidir con Kim (1996) e Ishikawa (1996), quienes señalan que existe una estrecha relación de la estructura del sistema con su oferta programática.

\section{Consumo}

Los datos que se presentan en esta sección, tanto de la muestra total como los que se analizan por género y por nivel socioeconómico, son mostrados por separado para cada ciudad, con el fin de respetar el hecho de que cada una tiene características que la distinguen, si bien el presente estudio no considera la distinción geográfica como una variable de análisis.

Preferencias programáticas por género. Para saber si existen diferencias en la manera que hombres y mujeres ven televisión, se establecieron relaciones entre las variables del estudio y el género. Una cuestión importante, para empezar, es saber si el género funciona como variable para determinar el gusto por ciertos tipos de programas televisivos. Los resultados parecen indicar que sí existe distinción en la frecuencia con que se ven varios tipos de programas, al usar la prueba $\mathrm{T}$ de Student para distinguir diferencias significativas entre las medias (véase tabla 5).

Los hombres de la Ciudad de México suelen ver "películas" de Estados Unidos y de otros países, programas de "aventuras" y de lo "insólito", programas "culturales", "deportes" y "comentarios deportivos" en mayor medida que las mujeres. Ellas prefieren las "telenovelas", las "películas" mexicanas y los programas "de chismes" en un grado más alto que los hombres.

El público masculino de Guadalajara prefiere "programas cómicos mexicanos", las "películas" de Estados Unidos y de otros países, los programas de "aventuras" y de lo "insólito", los programas "culturales", los "deportes" y los "comentarios deportivos". El público femenino suele ver "telenovelas", "di- 
bujos animados", comedia y programas "de chismes" en mayor grado que su contraparte masculina.

En resumen, los programas preferidos de cada género coinciden con los que han sido listados en otros países (Lemish, 1998; Lull, 1988; Morley, 1986; Muñoz, 1992). Llama la atención que los gustos masculinos sean especialmente consistentes en las tres ciudades. Tanto hombres como mujeres reportan que ven noticieros frecuentemente. Éstos aparecen como el tipo de programa más visto por los dos géneros, en todas las ciudades.

Comportamiento frente al televisor por género. ¿Cómo y quién decide lo que les gusta ver? Usando "Xi cuadrada" para comparar las muestras, se tiene que en Monterrey y Guadalajara sí hubo diferencia en la manera que hombres y mujeres deciden lo que ven por televisión, pero no así en México. Morley (1986) dice que los hombres suelen planear con anticipación lo que verán en la televisión, consultando la cartelera. En Monterrey y Guadalajara, el porcentaje de hombres que revisan la cartelera del periódico o consultan Tele Guía para seleccionar los programas que les interesan es mayor que el de mujeres, aunque en general no son muchas las personas que usan este sistema de decisión. Sin embargo, en ambas ciudades también es mayor el porcentaje de hombres que enciende la televisión sin un plan definido, sino que empieza a ver lo que hay en los diferentes canales y se detiene en el programa que llama su atención. En las mujeres es más común que conozcan el horario de los programas que les gustan y enciendan la televisión en el momento de su transmisión (véase tabla 6). Varios autores explican que las mujeres suelen realizar otras actividades, sobre todo quehaceres domésticos, cuando se exponen a la televisión (Covarrubias, 1998; Hobson, en Morley, 1992; Muñoz, 1992), mientras que los hombres generalmente la ven con total concentración (Covarrubias, Bautista y Uribe, 1994; Morley, 1992).

Para conocer la relación entre la exposición televisiva y otras actividades de la vida cotidiana, en el cuestionario aplicado se pregunta con qué frecuencia, al ver televisión, las personas hacen otras actividades. ${ }^{10}$ Sobresale el caso de los quehaceres domésticos, pues la diferencia se repite en las tres ciudades. La mayoría de los hombres nunca realiza labores domésticas mientras ve la televisión (Monterrey $=64.6 \%$, México $=73.8 \%$, Guadalajara $=69 \%$ ), y es bastante marcada la desigualdad con el porcentaje de mujeres que coinciden en esa respuesta (Monterrey $=29.2 \%$, México $=30.2 \%$, Guadalajara $=35.2 \%$ ).

10. El instrumento incluye varias actividades posibles: tareas escolares, quehaceres domésticos, lectura de periódicos, lectura de libros, conversación telefónica, conversación con miembros de la vivienda, desayuno, comida, cena, uso de computadora o Internet, juegos de video, pero aquí sólo se presentan el caso de los quehaceres domésticos por su especial relevancia. 
Ellas, en cambio, dicen que muy frecuentemente o regularmente cumplen con esta tarea frente a la televisión.

La serie de datos relacionados con el comportamiento frente al televisor fue recibida con gran subjetividad por parte del equipo investigador, influidos por su cosmovisión de género. Para Enrique Huerta (Huerta Wong, 2002), la aparente inmovilidad de los hombres frente al televisor podría significar: a) que los hombres realizan sus labores sin televisor y las mujeres frente a él; ${ }^{11}$ b) que las mujeres prefieren la radio sobre el televisor (también Llano, 1992); o, c) que los hombres no necesariamente se mantienen sin actividad laboral frente al televisor, pues podrían mirarla sin atención, ocupados en resolver mentalmente tareas de sus propias ocupaciones (Lull, 1988).

En cambio, para Aída Cerda y otras mujeres del equipo, la actividad femenina frente al televisor puede deberse a que las mujeres que son amas de casa perciben el hogar como un sitio de continuos quehaceres y responsabilidades. Ven en la evidencia que las posiciones diferenciadas de hombres y mujeres de la relación de cada género con la televisión muestran al hogar como "un lugar de esparcimiento para unos y de trabajos para otras" (Morley, 1992: 227-228). En cualquier caso, se puede ver un mejor acercamiento a los datos cualitativos, que dan cuenta de la compleja y contradictoria evidencia en este sentido (Huerta Wong, 2002).

Preferencias programáticas por nivel socioeconómico. Para saber si el nivel socioeconómico funciona como variable para determinar el gusto por ciertos tipos de programas televisivos, se hace un análisis de varianza. Aparecen diferencias significativas principalmente en "telenovelas", programas "cómicos", "películas" y programas "culturales". En las tres ciudades, los noticieros son el tipo de programa visto con mayor frecuencia, en todos los niveles socioeconómicos (véase tabla 7).

En general, las personas de Monterrey, México y Guadalajara dicen ver "telenovelas" frecuente o regularmente, pero sí aparecen diferencias significativas entre niveles. El nivel bajo reporta exponerse a ellas con mayor frecuencia que los niveles medio y alto. Este hallazgo no coincide con las afirmaciones de González (1998) y Covarrubias et al. (1994), en el sentido de que las "telenovelas" son productos "culturales" consumidos de igual manera por todas las clases sociales, pues aparentemente existe una distinción entre niveles, en especial del nivel socioeconómico bajo, respecto a los otros dos.

En cuanto a los otros tipos de programas donde aparecen diferencias, los resultados muestran que las personas de nivel socioeconómico bajo acostumbran ver programas cómicos de origen mexicano con mayor frecuencia, y

11. Llano, al entrevistar a mujeres de nivel socioeconómico bajo en Colombia, encontró que veían televisión mientras trabajaban y no en su tiempo libre, en el que preferían escuchar la radio. 
programas cómicos de origen estadounidense con menor frecuencia que las de niveles socioeconómicos medio y alto. Las "películas" mexicanas son preferidas en mayor grado por el nivel socioeconómico bajo, en comparación con el resto. Las "películas" de Estados Unidos son vistas con más frecuencia por el nivel socioeconómico alto. La exposición a "películas" de otros países rara vez se da en los tres niveles; sin embargo, la media es mayor en el nivel bajo, lo que significa que en este grupo es aún menor la frecuencia con que se ven. Las personas de nivel medio y alto dicen ver programas "culturales" regularmente, mientras que las de nivel socioeconómico bajo reportan que rara vez los ven.

Comportamiento frente al televisor por nivel socioeconómico. Los quehaceres domésticos se realizan viendo la televisión con mayor frecuencia en los niveles medio y bajo en Monterrey y México. En Monterrey no existe diferencia en la frecuencia con que se realiza la lectura de periódicos y libros, conversaciones telefónicas y con otros miembros de la vivienda, desayuno, cena, uso de computadora o Internet y juegos de video frente al televisor. $\mathrm{Al}$ hablar de México, se tiene que no hay diferencia en la frecuencia con que se leen libros, se conversa con miembros de la vivienda, y se realizan el desayuno, la comida y la cena. En Guadalajara no existe diferencia en la frecuencia con que se llevan a cabo estas actividades mientras se ve televisión: quehaceres domésticos, lectura de periódicos, lectura de libros, conversación con miembros de la vivienda, desayuno, comida, cena y juegos de computadora o gameboy.

La televisión se conecta de diversas maneras con otras tecnologías (Silverstone, 1996), y aquí puede verse que los niveles alto y medio hacen uso del teléfono, la computadora y los juegos de video mientras ven la televisión, con mayor frecuencia que el nivel bajo. Esto puede deberse más a la ausencia o uso restringido de dichos aparatos en el nivel socioeconómico bajo, que a otras razones de uso de la televisión en relación con las demás tecnologías.

\section{Conclusiones}

¿Qué y cómo se ve televisión en las áreas metropolitanas de Ciudad de México, Guadalajara y Monterrey? Como se ha dicho antes, conocer datos acerca de la televisión es importante, dado el papel central que tiene para los mexicanos este medio de comunicación. Pareció importante también hacer el estudio en estas tres áreas metropolitanas, donde radica una población equivalente a casi uno cada tres mexicanos. A continuación se ofrece un tipo de respuesta que, casi sobra decirlo, no es la única posible. 


\section{Oferta}

Como se ha mostrado a lo largo de este trabajo, la diversidad de la programación televisiva abierta en México es escasa. Kim (1996) expresa que a mayor diversidad en la estructura habrá mayor diversidad en la oferta. Aunque Ahn y Litman (1997) muestran que no es siempre así, parece haber cierta relación entre las variables que no hace sino mostrar la necesidad de análisis más sofisticados. La televisión mexicana proviene de una tradición comercial similar a la de Estados Unidos (Casas Pérez, 1995; Hernández Lomelí, 1992, 1993; Kim, 1996; Murphy, 1995). Mucha afinidad en la programación puede quizá ser explicada con Sánchez Ruiz (1996) y Biltereyst (1992), como producto de una afinidad cultural que rebasa al lenguaje como barrera y da como consecuencia una cierta interdependencia asimétrica. ${ }^{12}$

Podría especularse que la escasa diversidad programática sostiene algún grado de relación con la diversidad del sistema mediático, de donde se obtiene la mayor cantidad de programación importada ( $97 \%$ del total) de Estados Unidos (Lozano Rendón y Huerta Wong, 2001), cuyo escaso grado de diversidad ha sido revisado desde la programación o desde su diversidad cultural más o menos exhaustivamente (Ishikawa, 1996, Kim, 1996). Las importaciones pueden tener alguna función de establecimiento de agenda de la programación local. ${ }^{13}$ Esto no es más que especulación, y por supuesto, no se sugiere que haya una estadounidización de la cultura nacional. Sólo parece haber cierta relación en el sesgo de la concentración, particularmente en ficción, que presenta la oferta programática de ambos sistemas televisivos, y dada la tradición de importaciones estadounidenses, aun cuando parezca haber una tendencia a su disminución.

Una primera conclusión puede ser dada: el cumplimiento de la responsabilidad de la televisión abierta mexicana en 1999, de acuerdo con el ideal de servicio público deseable en una comunidad democrática, fue insatisfactorio al comportarse de manera excluyente.

12. Varis (1988) propuso durante los decenios de 1970 y 1980 que existía un flujo unidireccional de mensajes en el que los países más desarrollados fungían de productores y los países menos desarrollados, de audiencia. Esto, que con Norris y Pauling (1999) podemos tomar como cierto en alguna medida para los países no productores de programas televisivos, no lo es para México, cuyo sistema televisivo ocupa un lugar importante en el mundo. Concretamente en el caso de Estados Unidos, si bien es cierto que importan grandes cantidades de programación, las empresas televisivas mexicanas también le venden una cantidad importante de programas, particularmente para el consumo del mercado hispano, que suma casi 30 millones de personas. Sánchez Ruiz (1997) ha explicado que esto se debe, entre otras razones, a cierta afinidad cultural con nuestro vecino del norte. Al flujo de mensajes en dos vías se le ha denominado interdependencia asimétrica, por no ser igual la cantidad de productos culturales que entra a la que sale.

13. Para un desglose de las importaciones, véase Lozano Rendón y Huerta Wong, 2001. 


\section{Consumo}

Pareciera que el género funciona como una variable para marcar una distinción en la manera en que hombres y mujeres ven la televisión, por ejemplo, en cuanto a preferencias programáticas. Asimismo, el hallazgo reportado de que la mayoría de los hombres de Monterrey, México y Guadalajara nunca realizan labores domésticas mientras ven la televisión, y de que es bastante marcada la desigualdad con las mujeres en este aspecto particular -ellas, en cambio, dicen que muy frecuentemente o regularmente ven la televisión mientras cumplen con esta tarea-, apoya la idea manejada por algunos autores (Morley, 1992; Press, 1991; Walker, 1996) acerca de que la mujer no siente que el hogar sea un lugar de esparcimiento legítimo para ella, como lo es para el hombre, ya que la identidad masculina está relacionada más fuertemente que la suya con el trabajo fuera del hogar. La evidencia que ofrecen estos datos no es resultado inevitable de las características biológicas de las personas, sino que debe verse a la luz de una interpretación basada en el hecho de que el género es una categoría cultural. Lo que nos interesa es "la construcción cultural de las posiciones, subjetividades y dominios masculinos y femeninos y la articulación (o desarticulación) de las tecnologías en estos dominios culturalmente construidos" (Morley, 1992: 230). Por otro lado, tampoco esto es indicio claro de dominación androcéntrica al interior del espacio doméstico, como ha insistido Lull, y como se ha mostrado en otro lado (Huerta Wong, 2002).

El nivel socioeconómico aparece como un factor sumamente relacionado con el acceso a la cantidad y diversidad de contenidos televisivos. El número de aparatos de televisión por vivienda disminuye según el nivel socioeconómico; los niveles alto y medio tienen, en promedio, dos o más televisores. $\mathrm{El}$ porcentaje de viviendas que cuentan con televisión de paga va disminuyendo desde el nivel alto hacia el bajo. Además, el porcentaje de hogares que poseen videocasetera es mayor en los niveles alto y medio que en el nivel bajo.

Las características y las prácticas correspondientes a cada nivel socioeconómico se hacen presentes en los usos de la televisión, los modos de ver, la organización social del tiempo y el espacio cotidianos, por ejemplo idesde qué espacios se mira la televisión, públicos o privados? ¿Qué lugar ocupa el televisor en la casa, central o marginal? ¿Está encendido todo el día o solamente a la hora de las noticias?

Mientras que hay un nivel socioeconómico que a la televisión no le pide normalmente sino información, porque el entretenimiento y la cultura la busca en otros sitios [...], hay otros niveles socioeconómicos que todo eso se lo piden a la televisión (Martín-Barbero, 1987: 241). 
En resumen, los hallazgos parecen indicar que el género y el nivel socioeconómico funcionan para determinar el gusto por ciertos tipos de programas televisivos, pues se presentan distinciones en los programas a los que cada grupo acostumbra exponerse. Sería necesario analizar qué elementos del contenido o de la forma en que las audiencias se los apropian están participando en estas relaciones para llegar a entenderlas. Por ejemplo, aunque hay varios tipos de programas en los que no se presentan diferencias significativas en la frecuencia con que los diversos grupos acostumbran verlos, el caso de los noticieros es particularmente interesante porque en las tres localidades son programas vistos con mucha frecuencia, independientemente del género o del nivel socioeconómico del televidente.

\section{Discusión}

El diagnóstico sobre la oferta no trata de dar soluciones sino de evaluar, diagnosticar, revisar. Existe cierto consenso internacional acerca de que un sistema televisivo debe garantizar oportunidad de satisfacción de los intereses de la mayor parte posible de su audiencia y esto sólo parece posible aumentando el grado de diversidad. Cada país ha encontrado -o por lo menos buscado- soluciones diferentes a este problema, del cual la reglamentación es un primer paso. Para ampliar la diversidad, la reglamentación podría incluir el fortalecimiento de programas públicos en la televisión comercial, cuya naturaleza no parece posible de modificar, por lo menos no en el corto plazo. Y esa no es la única forma. Aumentar la competencia existente en las prácticas monopólicas del mercado televisivo mexicano podría ser otra manera, considerando que la estructura del sistema aparece estrechamente ligada a su programación.

Respecto al consumo, aún faltan muchas cosas por conocer acerca del lugar de los medios dentro de la vida cotidiana. En este trabajo se analizaron por separado algunos modos de relación con la televisión que distinguen a cada género y nivel socioeconómico, pero es necesario profundizar en la interacción entre las dos variables, pues la recepción de los medios es un proceso donde influyen múltiples características individuales y sociales para modelar nuestras prácticas.

Los hallazgos hablan de coincidencia con la evidencia internacional acerca del tema. Las audiencias mexicanas están expuestas a contenidos poco diversos, lo que contradice abiertamente el carácter de servicio público que podría tener la televisión abierta, sin menoscabo de sus ganancias. Los televidentes tienen escasa variedad en la oferta programática. Como ocurre en otros lugares del mundo, los hombres prefieren exponerse a programas " $\mathrm{de}$ portivos" y "de accion", mientras que las mujeres prefieren programas de "melodrama" y "de chismes". A diferencia de la evidencia recogida en otros 
países, en México las mujeres prefieren tanto como los hombres exponerse a "noticieros". Mientras ven la televisión, los hombres se instalan cómodamente, mientras que las mujeres prefieren constantemente realizar actividades, lo que podría hablar de desigualdades marcadas en la cultura mexicana. Asimismo, el nivel socioeconómico parece operar como un diferenciador democrático. Mientras mayor es el nivel socioeconómico, las audiencias parecen tener una oferta televisiva más diversa.

La televisión está al centro de la vida cotidiana. Ha transformado notoriamente las concepciones de espacio y tiempo, los temas de los que se habla y la forma de concebir los grandes eventos sociales, ya sea dentro y fuera del espacio doméstico. Por ello es preciso recuperar sus mensajes para el interés público. Aunque existen limitaciones metodológicas tan importantes en este trabajo, como la tipología a partir de la cual se preguntó a las audiencias sus preferencias programáticas, la demanda por contenidos informativos llama la atención sobre la falta de coincidencia de la demanda con la oferta programática existente. Es también posible que la falta de interés femenino por la televisión esté asociada con una marcada concentración de contenidos "masculinos", como los "deportes". Del mismo modo, la televisión abierta mexicana tendría que ser más diversa, a fin de que no sea más el nivel socioeconómico lo que garantice a las audiencias satisfacer sus intereses. La televisión ha de satisfacer a ciudadanos y no a consumidores, aunque aquí este último término se utilice, de modo más bien indiscriminado, en su vertiente clásica - compradores - y en la académica, es decir, receptores de mensajes.

Para ello, urge la discusión con base en evidencia sistemática, rigurosamente acumulada, que eventualmente permita un punto de partida sólido para la reglamentación de los medios de comunicación, permanentemente postergada y cuya discusión se ha hecho sin evidencia científica como punto de partida. Por supuesto, hacen falta análisis más holísticos que permitan conocer, por ejemplo, cómo son producidos los mensajes y qué impedimentos estructurales se tienen para no satisfacer los intereses sociales, o cómo las audiencias apropian y resignifican en su vida cotidiana los mensajes a los que son expuestos.

Tabla 1

Composición de la muestra de la encuesta por ciudad

\begin{tabular}{|l|c|c|c|c|c|c|c|}
\hline \multicolumn{1}{|c|}{ Ciudad } & $\mathbf{N}$ & $\mathbf{n}$ & \multicolumn{2}{c|}{ Género } & \multicolumn{3}{c|}{ Nivel socioeconómico } \\
\hline & & & Masculino & Femenino & Alto & Medio & Bajo \\
\hline Monterrey & $1^{\prime} 672,144$ & 986 & 243 & 740 & 121 & 472 & 393 \\
\hline México & $5 ' 579,531$ & 802 & 298 & 498 & 69 & 338 & 395 \\
\hline Guadalajara & $1^{\prime} 785,604$ & 900 & 319 & 553 & 55 & 363 & 482 \\
\hline Total & & 2,688 & 860 & 1,791 & 245 & 1,173 & 1,270 \\
\hline
\end{tabular}


Tabla 2

\section{Tipo por semana}

\begin{tabular}{|c|c|c|c|c|}
\hline & Semana 1 & Semana 2 & Semana 3 & Semana \\
\hline Género & $\%$ & $\%$ & $\%$ & $\%$ \\
\hline Dibujos animados & 22.1 & 16.7 & 17.1 & 19.9 \\
\hline Película & 18.4 & 13.6 & 15.9 & 11.6 \\
\hline Magazine (noticias, entrevistas y música) & 9.0 & 13.8 & 11.6 & 11.0 \\
\hline Telenovelas & 8.9 & 10.6 & 10.6 & 10.1 \\
\hline \begin{tabular}{|l|} 
Noticiero \\
\end{tabular} & 6.1 & 13.1 & 7.9 & 11.2 \\
\hline Musicales & 3.6 & 3.4 & 2.5 & 3.4 \\
\hline Serie de comedia & 3.4 & 1.6 & 1.0 & 0.1 \\
\hline Juegos y concursos & 3.3 & 3.1 & 3.1 & 2.1 \\
\hline Transmisión de juegos o competencias & 3.2 & 4.4 & 4.4 & 6.0 \\
\hline Humorísticos & 3.1 & 1.0 & 1.0 & 2.3 \\
\hline Comentarios, análisis, entrevistas & 2.5 & 3.4 & 2.7 & 3.2 \\
\hline Series infantiles & 2.3 & 4.3 & 4.7 & 1.2 \\
\hline Programas de ventas directas al público & 2.2 & 0.5 & 6.3 & 7.4 \\
\hline Talk show-chat & 2.0 & 1.8 & 4.0 & 3.6 \\
\hline Actividades y concursos & 1.9 & 2.0 & 1.3 & 3.5 \\
\hline Videos de aficionados & 1.8 & & 0.7 & 0.7 \\
\hline Televerdad & 1.5 & & & \\
\hline Serie de aventura o acción & 0.8 & 0.4 & 1.2 & 0.7 \\
\hline Cómicos & 0.7 & 1.6 & 0.9 & \\
\hline Documentales & 0.7 & 0.6 & 0.8 & 0.6 \\
\hline Serie de terror o sobrenatural & 0.6 & 0.2 & 0.2 & \\
\hline Entrevista y debate & 0.4 & & & 0.2 \\
\hline Acto cívico & 0.2 & & & \\
\hline Cocina & 0.2 & 0.3 & 0.2 & 0.3 \\
\hline Crónica social & 0.2 & & & \\
\hline Musicales & 0.2 & & 0.2 & 0.2 \\
\hline Serie de ciencia ficción & 0.2 & 0.4 & & \\
\hline Serie de drama-teleteatro & 0.2 & 0.2 & 0.2 & 0.2 \\
\hline Partidos políticos & 0.0 & 0.0 & 0.1 & \\
\hline Propaganda política pagada & 0.0 & 0.0 & & 0.1 \\
\hline Asistencia social & & 0.5 & & \\
\hline Comentarios humorísticos & & 0.3 & & \\
\hline Cursos de educación formal & & 0.6 & & \\
\hline Didácticos & & 0.1 & & \\
\hline \begin{tabular}{|llll}
$\begin{array}{l}\text { Dramatizaciones } \\
\text { asesinatos }\end{array}$ & de accidentes, & \\
\end{tabular} & & 0.2 & 0.6 & \\
\hline Pseudo-ciencia & & & 0.2 & \\
\hline Reportajes & & 0.1 & 0.5 & 0.1 \\
\hline Reseñas, cortos y makings de películas & & & & 0.1 \\
\hline Serie de suspenso & & 0.6 & & \\
\hline Serie policiaca & & 0.5 & & \\
\hline Minutos totales & 28,340 & 29,635 & 30,270 & 29,600 \\
\hline Total & 100 & 100 & 100 & 100 \\
\hline
\end{tabular}


Tabla 3. Diversidad vertical por tipo

\begin{tabular}{|c|c|c|c|c|c|}
\hline Tipo & 2 Televisa & 5 Televisa & $\begin{array}{l}7 \text { TV } \\
\text { Azteca }\end{array}$ & $\begin{array}{l}13 \mathrm{TV} \\
\text { AzIeca }\end{array}$ & Total \\
\hline \multirow[t]{2}{*}{ Noticiers } & 2.525 & & 2.325 & 6.475 & 11.325 \\
\hline & $8.2 \%$ & & $8.4 \%$ & $22.2 \%$ & $9.6 \%$ \\
\hline \multirow[t]{2}{*}{ Entrevista y debate } & 180 & & & & 180 \\
\hline & $6 \%$ & & & & $.2 \%$ \\
\hline Mogazine (noticias. & 8,520 & & 30 & +.890 & 13.440 \\
\hline entrevistas y música) & $27.6 \%$ & & $0.1 \%$ & $16.8 \%$ & $11.4 \%$ \\
\hline Comentarios humoristicos & & & $\begin{array}{c}90 \\
0.3 \%\end{array}$ & & $\begin{array}{c}90 \\
0.1 \%\end{array}$ \\
\hline \multirow[t]{2}{*}{ Pclícula } & 3,030 & 7,212 & 3.870 & 3.390 & 17,505 \\
\hline & $9.8 \%$ & $23.9 \%$ & $1+\%$ & $11.6 \%$ & $14.9 \%$ \\
\hline \multirow[t]{2}{*}{ Cómicos } & 180 & & $9 n$ & 390 & 960 \\
\hline & $1.6 \%$ & & $0.3 \%$ & $1.3 \%$ & $0.81 \%$ \\
\hline \multirow[t]{2}{*}{ Telenovelas } & 5.940 & & $3+0$ & 5,400 & 11,880 \\
\hline & $19.3 \%$ & & $1.9 \%$ & $18.5 \%$ & $10.1 \%$ \\
\hline Telcverdad & & & & $\$ 20$ & +20 \\
\hline & & & & $1.4 \%$ & $0.4 \%$ \\
\hline Talk show-chot & 1320 & 135 & 150 & 1,770 & 3,375 \\
\hline & $4.3 \%$ & $0.4 \%$ & $0.5 \%$ & $6.1 \%$ & $2.9 \%$ \\
\hline Pseudo-ciencia & & 60 & & & 60 \\
\hline & & $0.2 \%$ & & & $0.1 \%$ \\
\hline Dramatiraciones de & & 120 & 120 & & 240 \\
\hline accidentes, robos, asesinatos & & $0.4 \%$ & $0.4 \%$ & & $0.2 \%$ \\
\hline Videos de aficionados & & & $5+0$ & 390 & 930 \\
\hline & & & $1.9 \%$ & $1,3 \%$ & $0.8 \%$ \\
\hline Juegos y concursos & 2,185 & & 1.050 & 180.6 & 3,415 \\
\hline & $7.1 \%$ & & $3.8 \%$ & & $2.9 \%$ \\
\hline Musicales & 1,560 & & 402 & 1,850 & 3,830 \\
\hline & $5.1 \%$ & . & $1.5 \%$ & $6.3 \%$ & $3.3 \%$ \\
\hline Cocina & & & & 285 & 285 \\
\hline & & & & $1 \%$ & $.2 \%$ \\
\hline Humoristicos & 690 & 290 & 240 & 930 & 2,150 \\
\hline & $2.2 \%$ & $1 \%$ & $.9 \%$ & $3.2 \%$ & $1.8 \%$ \\
\hline Cronica social & & & & 60 & 60 \\
\hline & & & & $.2 \%$ & $.1 \%$ \\
\hline Asistencia social & 135 & & & & 135 \\
\hline & $0.4 \%$ & . & & & $.1 \%$ \\
\hline Reseñas, cortos : adelantos de & & & 30 & & 30 \\
\hline peliculas & & & 0.1 & & $\mathbf{0}$ \\
\hline Actividades y concursos & 960 & 1,020 & 600 & & 2,580 \\
\hline & $3.1 \%$ & $3.4 \%$ & $2.2 \%$ & & $2.2 \%$ \\
\hline Dibujos animados & & 17.940 & $\$ .230$ & 120 & 22,290 \\
\hline & & $59.5 \%$ & $15.3 \%$ & $0.4 \%$ & $18.9 \%$ \\
\hline Series infantiles & 180 & 1,200 & 2,320 & & 3.700 \\
\hline & $0.6 \%$ & $0.4 \%$ & $8.4 \%$ & & $3.1 \%$ \\
\hline Musicales & 180 & & & & 180 \\
\hline & $0.6 \%$ & & & & $0.2 \%$ \\
\hline Didácticos & & & 30 & & 30 \\
\hline & & & $0.1 \%$ & & $0 \%$ \\
\hline Comentarios, análisis, & 860 & & 1,560 & 1,065 & 3,483 \\
\hline entrevistas & $2.8 \%$ & & $5.6 \%$ & $3.7 \%$ & $3 \%$ \\
\hline Transmisión de juegos o & 1,035 & 210 & 2,685 & 1.380 & 5,310 \\
\hline competcncias & $3.4 \%$ & $0.7 \%$ & $9.7 \%$ & $4.7 \%$ & $+.5 \%$ \\
\hline Documentales & 690 & & 90 & 30 & 810 \\
\hline & $2.2 \%$ & & $0.3 \%$ & $0.1 \%$ & $0.7 \%$ \\
\hline Reportajes & 90 & & & 1211 & 2301 \\
\hline & $0.3 \%$ & & & $0 .+\%$ & $0.2 \%$ \\
\hline Cursos de cducación formal & & & 180 & & 180 \\
\hline & & & $0.6 \%$ & & $0.2 \%$ \\
\hline Programas de ventas directas & 15 & & 4,890 & & 4,890 \\
\hline al público & $0 \%$ & & $17.6 \%$ & & $4.1 \%$ \\
\hline Propaganda politica pagada & & 20 & & & 35 \\
\hline & & $0.1 \%$ & & & $0 \%$ \\
\hline Partidos políticos & & 50 & & & 30 \\
\hline & & $0.2 \%$ & & & $m$ \\
\hline Acto civico & & 30 & 15 & & 15 \\
\hline & & $0.1 \%$ & $0.1 \%$ & & $0 \%$ \\
\hline Serie de comedia & & 140 & 1.635 & & 1,775 \\
\hline & & $0.5 \%$ & $5.9 \%$ & & $1.5 \%$ \\
\hline Serie de aventura o acción & & 930 & & & 930 \\
\hline & & $3.1 \%$ & & & $0.8 \%$ \\
\hline Serie de drama-teleteatro & 240 & & & & 240 \\
\hline & $0.8 \%$ & & & & $0.2 \%$ \\
\hline Serie de suspenso & & 180 & & & 180 \\
\hline & & $0.6 \%$ & & & $0.2 \%$ \\
\hline Serie de ciencia ficción & & 170 & & & 170 \\
\hline & & $0.6 \%$ & & & $0.1 \%$ \\
\hline Serie de terror o sobrenatural & & 290 & & & 290 \\
\hline & & $1 \%$ & & & $2 \%$ \\
\hline Senc policiaca & & 155 & & & 155 \\
\hline & & $0.5 \%$ & & & $0.1 \%$ \\
\hline Total & $\begin{array}{c}30,815 \\
100 \%\end{array}$ & $\begin{array}{l}30,155 \\
100 \%\end{array}$ & $\begin{array}{c}27.730 \\
100 \%\end{array}$ & $\begin{array}{c}29.145 \\
10 \% \%\end{array}$ & $\begin{array}{c}n=117,845 \\
100 \%\end{array}$ \\
\hline
\end{tabular}


Tabla 4. Diversidad horizontal por tipo

\begin{tabular}{|c|c|c|c|c|}
\hline Tipo & Honario $\mathrm{A}$ & Honario & $\begin{array}{l}\text { Homitio } \\
\text { AMA }\end{array}$ & Toeal \\
\hline Noticiero & $\begin{array}{l}6,930 \\
11,9 \%\end{array}$ & $\begin{array}{l}1,1+0 \\
4.4 \%\end{array}$ & $\begin{array}{l}3.255 \\
9.6 \% \\
\end{array}$ & $\begin{array}{l}71,325 \\
9,6 \%\end{array}$ \\
\hline Entrevista y debate & & & $\begin{array}{l}190 \\
.9 \%\end{array}$ & .246 \\
\hline Magazine (noticias, entrevistas y múcica) & $\begin{array}{l}13,000 \\
22.5 \%\end{array}$ & $\begin{array}{l}300 \\
1.2 \% \\
\end{array}$ & .60 & $\begin{array}{l}13,440 \\
11.4 \% \\
\end{array}$ \\
\hline Comentarios humoristicos & & & $3 \%$ & $\begin{array}{l}10 \\
.1 \%\end{array}$ \\
\hline Pelicula & $\begin{array}{l}6.135 \\
10.5 \% \\
\end{array}$ & $\begin{array}{l}4.355 \\
17.6 \%\end{array}$ & $\begin{array}{l}6,815 \\
20.2 \%\end{array}$ & $\begin{array}{l}17,505 \\
14.9 \%\end{array}$ \\
\hline Cónicos & $1 \%$ & $\begin{array}{l}5110 \\
2 \%\end{array}$ & $\begin{array}{l}3 \% 9 \\
1.2 \%\end{array}$ & 86 \\
\hline Telenovelas & $\begin{array}{r}30 \\
.1 \%\end{array}$ & $\begin{array}{l}4,530 \\
17.5 \%\end{array}$ & $\begin{array}{l}7,320 \\
21.7 \%\end{array}$ & $\begin{array}{l}11,280 \\
10.1 \%\end{array}$ \\
\hline Televerdad & $\begin{array}{l}180 \\
3 \%\end{array}$ & $\begin{array}{l}240 \\
.9 \%\end{array}$ & & $4.4 \%$ \\
\hline Talk show/Chat & .48 & $\begin{array}{l}1,390 \\
3 \%\end{array}$ & $\begin{array}{l}1.605 \\
4.7 \%\end{array}$ & $\begin{array}{l}3,375 \\
2.9 \%\end{array}$ \\
\hline Pseudo-ciencin & & & $\begin{array}{l}.26 \\
.20\end{array}$ & $\begin{array}{l}60 \\
.1 \%\end{array}$ \\
\hline $\begin{array}{l}\text { Dramatizaciones de accidernas, robos, } \\
\text { aesesinatos }\end{array}$ & & .60 & 190 & $2 \%$ \\
\hline Videos de aficionados & $\begin{array}{l}390 \\
.7 \%\end{array}$ & $.2 \%$ & $\begin{array}{l}4.80 \\
1.4 \%\end{array}$ & 830 \\
\hline Juegos y concursos & $\begin{array}{l}860 \\
1.5 \%\end{array}$ & $\begin{array}{l}1560 \\
6 \%\end{array}$ & $2.9 \%$ & $\begin{array}{l}3,415 \\
2.9 \%\end{array}$ \\
\hline Musiceles & $\begin{array}{l}810 \\
1.4 \%\end{array}$ & $\begin{array}{l}660 \\
2.6 \%\end{array}$ & $\begin{array}{c}2,3,360 \\
7 \%\end{array}$ & $\begin{array}{l}-3,830 \\
3,3 \%\end{array}$ \\
\hline Cocin & $\begin{array}{l}2.53 \\
.5 \%\end{array}$ & & & .285 \\
\hline Humorísticos & $\begin{array}{l}9.30 \\
1.6 \%\end{array}$ & .90 & $\begin{array}{l}1.130 \\
3.3 \%\end{array}$ & $\begin{array}{l}2.150 \\
1.8 \%\end{array}$ \\
\hline Crónica social & $\begin{array}{l}60 \\
.1 \%\end{array}$ & & & $\begin{array}{r}60 \\
.10 \%\end{array}$ \\
\hline Asistencia social & 120 & & 13 & 135 \\
\hline Reseñas, cortos y adelantos de peliculas & $\begin{array}{l}30 \\
.1 \%\end{array}$ & & & $\begin{array}{l}30 \\
0 \%\end{array}$ \\
\hline Actividades y concursos & $\begin{array}{l}2,040 \\
3.5 \%\end{array}$ & $\begin{array}{r}540 \\
2.1 \%\end{array}$ & & $\begin{array}{l}2,580 \\
2.2 \%\end{array}$ \\
\hline Dibujos animedos & $\begin{array}{l}13.290 \\
22.8 \%\end{array}$ & $\begin{array}{l}6,150 \\
23.8 \%\end{array}$ & $\begin{array}{l}2,850 \\
8.4 \%\end{array}$ & $\begin{array}{l}22,290 \\
18,9 \%\end{array}$ \\
\hline Scries infantiles & $\begin{array}{l}1,830 \\
3.1 \%\end{array}$ & $\begin{array}{l}1,870 \\
7.2 \%\end{array}$ & & $\begin{array}{l}3,700 \\
3.1 \%\end{array}$ \\
\hline Musicales & $\begin{array}{l}180 \\
.3 \%\end{array}$ & & & 180 \\
\hline Didacticos & $\begin{array}{l}30 \\
.1 \%\end{array}$ & & & ox \\
\hline Comentarios, análisis, entrevistas & $\begin{array}{l}1,920 \\
3,3 \%\end{array}$ & $\begin{array}{l}660 \\
2.6 \%\end{array}$ & $\begin{array}{l}005 \\
2.7 \%\end{array}$ & $\begin{array}{c}3,495 \\
3 \%\end{array}$ \\
\hline Transmisión de jucgos o compeckncins & $\begin{array}{r}2,425 \\
+.2 \%\end{array}$ & $\begin{array}{l}1,460 \\
37 \%\end{array}$ & $\begin{array}{l}1,423 \\
4.7 \%\end{array}$ & $\begin{array}{l}5,310 \\
4,5 \%\end{array}$ \\
\hline Documentales & $\begin{array}{l}360 \\
.6 \%\end{array}$ & 60 & $\begin{array}{r}390 \\
1.2 \%\end{array}$ & $\begin{array}{l}10 \\
7 \%\end{array}$ \\
\hline Reportajes & $\begin{array}{l}60 \\
.1 \%\end{array}$ & $\begin{array}{l}30 \\
.1 \%\end{array}$ & .120 & $2 \%$ \\
\hline Cursos de educacion formal & $\begin{array}{l}100 \\
.3 \%\end{array}$ & & & $\begin{array}{l}.20 \\
.2 \%\end{array}$ \\
\hline Progranas de ventas directas al público & $\begin{array}{l}+.690 \\
8.48\end{array}$ & & & $\begin{array}{l}4,890 \\
4.1 \%\end{array}$ \\
\hline Propaganda politica pagada & & & .18 & $3 \%$ \\
\hline Panidos políticos & & & $\begin{array}{l}.10 \\
.16 \\
.1 \%\end{array}$ & $\begin{array}{l}50 \\
0 \times \\
0 \times\end{array}$ \\
\hline Acto civico & $\begin{array}{l}30 \\
.1 \%\end{array}$ & & $\begin{array}{l}15 \\
0 \%\end{array}$ & $\begin{array}{l}15 \\
0 \%\end{array}$ \\
\hline Serie de concedia & $\begin{array}{l}600 \\
1 \%\end{array}$ & 20 & $\begin{array}{l}1,115 \\
3.3 \%\end{array}$ & $\begin{array}{l}1,775 \\
1.5 \%\end{array}$ \\
\hline Serie de aventura o accion & & & $\begin{array}{r}930 \\
2.8 \% \\
\end{array}$ & $\begin{array}{l}930 \\
.8 \%\end{array}$ \\
\hline Serie de drama-teleteatro & & & $\begin{array}{l}240 \\
7 \%\end{array}$ & $\begin{array}{l}240 \\
2 \%\end{array}$ \\
\hline Serie de suspenso & & & $\begin{array}{l}180 \\
.5 \%\end{array}$ & $\begin{array}{l}180 \\
24\end{array}$ \\
\hline Serie de ciencia frocion & & & $\begin{array}{l}170 \\
5 \%\end{array}$ & $\begin{array}{l}170 \\
.1 \%\end{array}$ \\
\hline \multicolumn{5}{|l|}{ Serie de vemor o sobrenetural } \\
\hline Serie policiach & & & & \\
\hline Total & $\begin{array}{l}58,215 \\
100 \%\end{array}$ & $\begin{array}{c}20,025 \\
100 \%\end{array}$ & $\begin{array}{c}33,005 \\
100 \%\end{array}$ & $\begin{array}{c}1178+5 \\
100 \%\end{array}$ \\
\hline Valores perdidos $=3,375(2.8 \%)$ & $\begin{array}{c}x= \\
52=39,144 \\
p=0001\end{array}$ & & & \\
\hline
\end{tabular}


Tabla 5. ¿Qué tanto acostumbra ver diversos tipos de programas? Por género

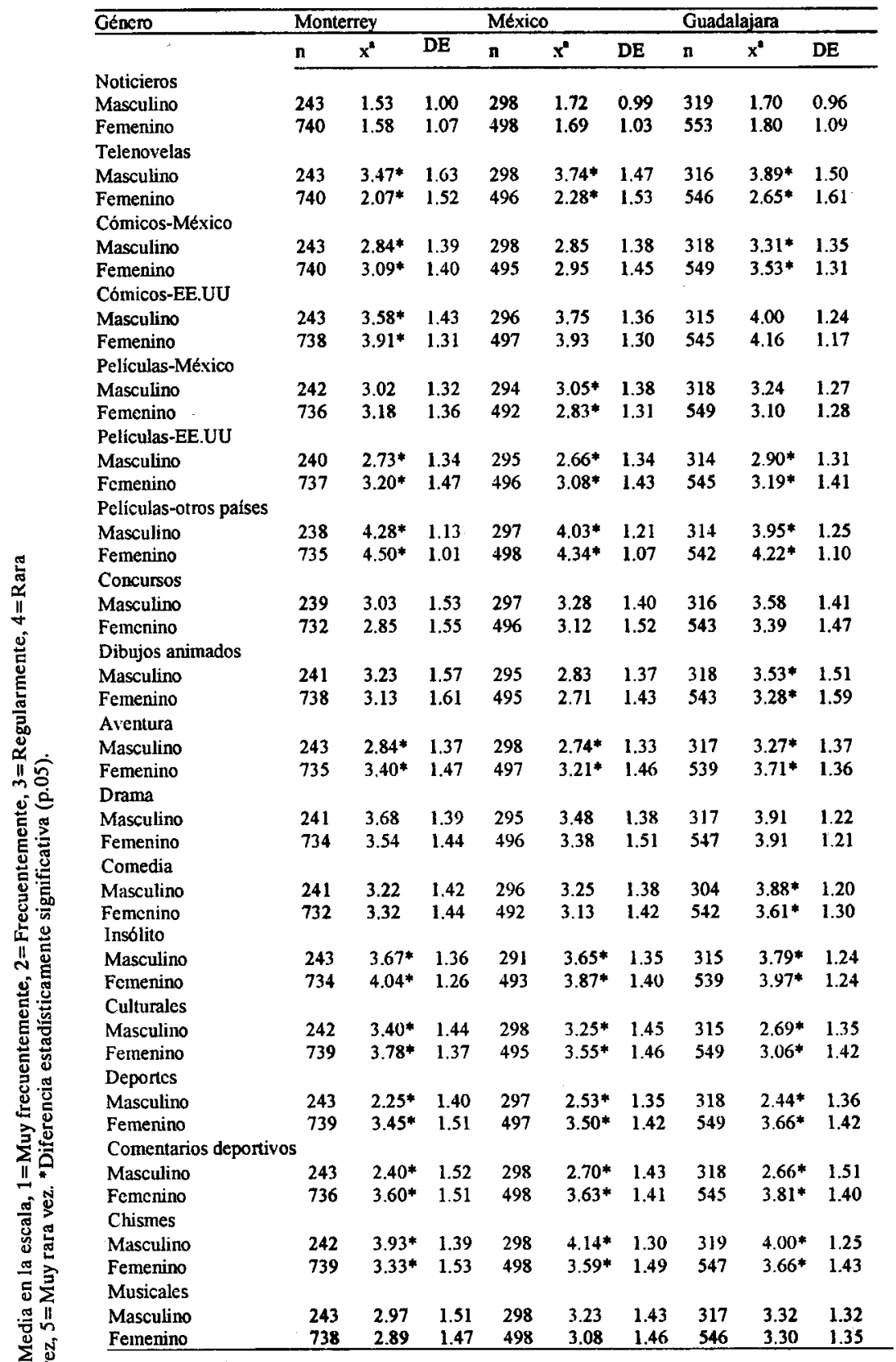


Tabla 6

¿Cómo acostumbra decidir lo que ve en la televisión? Por género

\begin{tabular}{|c|c|c|}
\hline 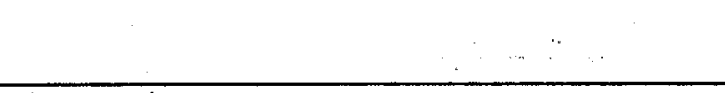 & $\begin{array}{l}\text { Masculino } \\
\%\end{array}$ & $\begin{array}{l}\text { Femenino } \\
\%\end{array}$ \\
\hline \multicolumn{3}{|l|}{ Monterrey* } \\
\hline $\begin{array}{l}\text { Consulto la cartelera de TV del periódico o del Tele } \\
\text { Guía y selecciono los programas que me interesan }\end{array}$ & 13.2 & 5.0 \\
\hline $\begin{array}{l}\text { Conozco los horarios de mis programas favoritos y los } \\
\text { sintonizo de acuerdo a la hora }\end{array}$ & 49.0 & 58.2 \\
\hline $\begin{array}{l}\text { No tengo un plan definido. Prendo la TV y empiezo a } \\
\text { ver lo que hay en los diferentes canales y me detengo } \\
\text { en el programa que me llama la atención }\end{array}$ & 34.6 & 29.9 \\
\hline $\begin{array}{l}\text { Veo lo que otros miembros de la vivienda decidieron } \\
\text { sintonizar }\end{array}$ & 0.4 & 3.0 \\
\hline Varias de las opciones & 2.9 & 3.9 \\
\hline Total & $\begin{array}{l}100 \% \\
\mathrm{n}=243\end{array}$ & $\begin{array}{l}100 \% \\
\mathrm{n}=740\end{array}$ \\
\hline \multicolumn{3}{|l|}{ México } \\
\hline $\begin{array}{l}\text { Consulto la cartelera de TV del periódico o del Tele } \\
\text { Guía y sclccciono los programas que me interesan }\end{array}$ & 5.7 & 3.4 \\
\hline $\begin{array}{l}\text { Conozco los horarios de mis programas favoritos y los } \\
\text { sintonizo de acuerdo a la hora }\end{array}$ & 42.6 & 47.2 \\
\hline $\begin{array}{l}\text { No tengo un plan definido. Prendo la TV y empiezo a } \\
\text { ver lo que hay en los diferentes canales y me detengo } \\
\text { en el programa que me llama la atención }\end{array}$ & 43.0 & 40.0 \\
\hline $\begin{array}{l}\text { Veo lo que otros miembros de la vivienda decidieron } \\
\text { sintonizar }\end{array}$ & 1.7 & 3.4 \\
\hline Varias de las opciones & 7.0 & 6.0 \\
\hline$\therefore \quad 51$ & $\begin{array}{l}100 \% \\
\mathrm{n}=298\end{array}$ & $\begin{array}{l}100 \% \\
\mathrm{n}=498 \\
\end{array}$ \\
\hline \multicolumn{3}{|l|}{ Guadalajara* } \\
\hline $\begin{array}{l}\text { Consulto la cartelera de TV del periódico o del Tele } \\
\text { Guia y selecciono los programas que me interesan }\end{array}$ & 14.1 & 8.2 \\
\hline $\begin{array}{l}\text { Conozco los horarios de mis programas favoritos y los } \\
\text { sintonizo de acuerdo a la hora }\end{array}$ & 34.2 & 44.9 \\
\hline $\begin{array}{l}\text { No tengo un plan definido. Prendo la TV y empiezo a } \\
\text { ver lo que hay en los diferentes canales y me detengo } \\
\text { en el programa que me llama la atención }\end{array}$ & 45.8 & 39.6 \\
\hline $\begin{array}{l}\text { Veo lo que otros miembros de la vivienda decidieron } \\
\text { sintonizar }\end{array}$ & 1.3 & 3.3 \\
\hline Varias de las opciones & 4.7 & 4.0 \\
\hline Total & $\begin{array}{l}100 \% \\
\mathrm{n}=319\end{array}$ & $\begin{array}{l}100 \% \\
\mathrm{n}=550\end{array}$ \\
\hline
\end{tabular}

*Diferencia estadísticamente significativa $(p=0.001)$ 
Tabla 7. ¿Qué tanto acostumbra ver diversos tipos de programas?

Por nivel socioeconómico

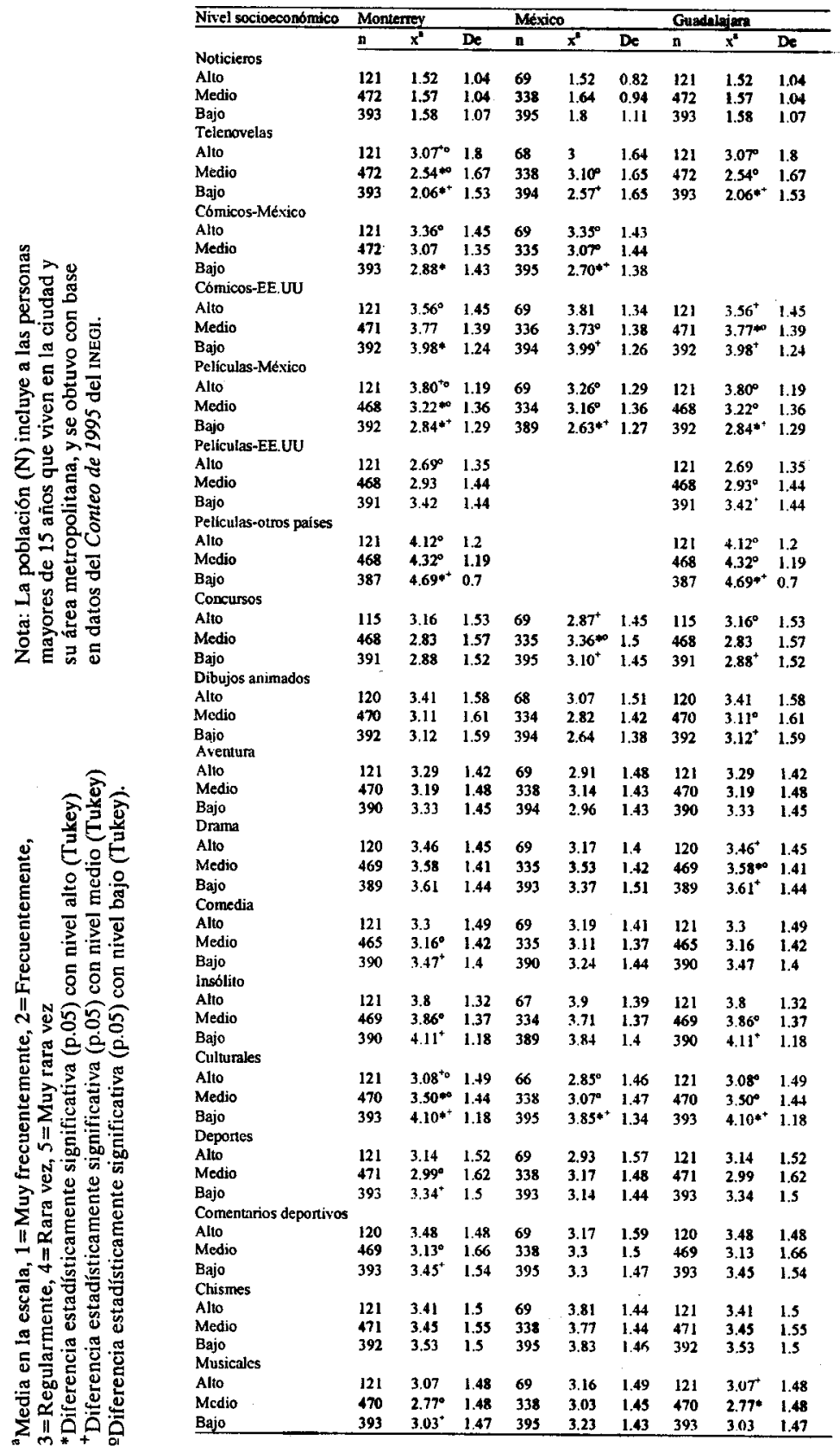




\section{Bibliografía}

(1997), “¿Anunciarse en televisión abierta?”, en Expansión, 22 de octubre, pp. 68-77.

Ahn, H. y Litman, B. R. (1997), "Vertical Integration and Consumer Welfare in the Cable Industry", en Journal of Broadcasting \& Electronic Media, 41 (4), pp. 453-477.

Barrios, Leoncio, en G. Orozco Gómez (coord.) (1992), Miradas latinoamericanas a la televisión, México, Universidad Iberoamericana, pp. 55-74.

Biltereyst, D. (1992), "Language and Culture as Ultimate Barriers?: An Analysis of the Circulation, Consumption and Popularity of Fiction in Small European Countries", en European Journal of Communication, 7, pp. 517-540.

Casas Pérez, M. L. (1995), "Los otros actores de la TV: otra forma de pensar a la televisión desde la política", en C. Gómez Mont (coord.), La metamorfosis de la $T V$, tomo 8, México, UIA/PROIICOM.

Corral, J. (2001), "Manifiesto contra la telebasura. Etcétera", en: www.afavordelomejor.org.

Covarrubias, K. (1998), “iCórrele que ya empezó...! La familia y las telenovelas", en J. González (comp.), La cofradia de las emociones (in)terminables: Miradas sobre telenovelas en México, Guadalajara, Universidad de Guadalajara, pp. 278-311.

Covarrubias, K., Bautista, A. y Uribe, A. (1994), Cuéntame en qué se quedó: La telenovela como fenómeno social, México, Trillas.

Crovi Druetta, D. (ed.) (1995), Desarrollo de las industrias audiovisuales en México y Canadá, México, Facultad de Ciencias Políticas y Sociales de la Universidad Nacional Autónoma de México.

Datos de IBOPE sobre las características de los televidentes en México (1996, noviembre-diciembre), en Telemundo, 5(32), 9.

González, J. (comp.) (1998), La cofradía de las emociones (in)terminables: Miradas sobre telenovelas en México, Guadalajara, Universidad de Guadalajara.

Hernández Lomelí, F. (1992-1993), “Televisa en España”, en Comunicación y Sociedad (16/17), pp. 75-104.

Gutiérrez Gea, C. (2000), "Televisión y calidad: perspectivas de investigación y criterios de evaluación", en ZER Revista de Estudios de Comunicación, (9), en: http://www.ehu.es/zer/

Huerta, C. (1999), “Es TV juguete favorito...", en El Norte, 25 de septiembre, p. A2. 
Huerta Wong, J. E. (2002), Negociación entre los géneros en el acto de ver televisión, memorias del XXXII Congreso de Investigación y Extensión del Sistema ITESM, Monterrey, México, 17-18 de enero (una versión de este trabajo se puede encontrar en Comunicación y Sociedad (43), en prensa).

Huerta Wong, J. E. (1999), "Percepción de la violencia en televidentes del área metropolitana de Monterrey", en Comunicación y Sociedad, 36, pp. 199-226.

Hultén, O. (1995), "Diversity or conformity? Television programming in competitive situations", en The Nordicom Review, 1, pp. 7-21.

Instituto Nacional de Estadística, Geografía e Informática (1996), Encuesta Nacional de Ingresos y Gastos de los Hogares, Aguascalientes, INEGI.

Ischii, K., H. Su y S. Watanabe (1999), "Japanese and Us programs in Taiwan: New patterns in Taiwanese television", en Journal of Broadcasting and Electronic Media, 43 (3), pp. 416-431.

Ishikawa, Sakae (ed.) (1996), Quality Assessment of Television, Gran Bretaña, University of Luton Press.

Jara Elías, J. R. (1997), "Las audiencias de la televisión en español en América Latina", en Revista Mexicana de Comunicación (51), pp. 14-17.

Kim, D. (1996), Television Program Diversity and Media Structure: a Cross National Comparative Study, tesis doctoral, Universidad de Texas en Austin.

Lemish, D. (1998), "Girls can Wrestle Too: Gender Differences in the Consumption of a Television Wrestling Series", en Sex Roles, 38(9/10), pp. 833-849.

Litman, B. y Hasegawa, K. (1996), "Measuring Diversity in US Television Programming: New Evidence", en S. Ishikawa (ed.), Quality Assessment of Television, Gran Bretaña, University of Luton Press, pp. 203-230.

Llano, C. (1992), "Usos sociales de la televisión y de la telenovela: La telenovela en el barrio popular", en Martín-Barbero, Jesús y Muñoz, Sonia (coords.), Televisión y Melodrama, Colombia, Tercer Mundo Editores, pp. 215-231.

López Islas, J. R. y Cerda Cristerna, A. (1999), "Violencia en la televisión mexicana: Un análisis del contenido de los treinta programas con mayor nivel de audiencia", en Hiper-textos, 2, disponible el 30 de mayo de 2000 , en: www.mty.itesm.mx/dcic/hiper-textos.

Lozano, J. C. (1997), "Oferta y consumo de contenidos televisivos transnacionales en México", ponencia presentada en la XL Conferencia Anual de la Asociación Internacional de Estudios de Comunicación Social, Oaxaca, julio. 
Lozano, J. C. (1995-1996), "Oferta y recepción de televisión extranjera en México", en Comunicación y Sociedad, núms. 25-26, pp. 259-284.

Lozano Rendón, J. C. y Huerta Wong, J. E. (2001), "La programación televisiva mexicana de 1999 desde la perspectiva de la diversidad", en Cerdán Díaz, J. L. y Aceves González, F. (eds.), Anuario de Investigación de la Comunicación Coneicc VIII, México: Coneicc, pp. 197-221.

Martín-Barbero, J. (1987), De los medios a las mediaciones: Comunicación, cultura y hegemonía, México, Gustavo Gili.

McQuail, D. (1998), La acción de los medios: Los medios de comunicación y el interés público, Buenos Aires, Amorrortu Editores.

Morley, D. (1992), Television, Audiences and Cultural Studies, Londres, Routledge.

Morley, D. (1986), Family Television: Cultural Power and Domestic Leisure, Londres, Comedia.

Morley, D. y Silverstone, R. (1994), “Comunicación y contexto", en Versión (4), pp. 69-87.

Muñoz, S. (1992), "Mundos de vida y modos de ver", en J. Martín-Barbero y S. Muñoz (coords.), Televisión y melodrama: Géneros y lecturas de la telenovela en Colombia, Bogotá, Tercer Mundo, pp. 233-294.

Murphy, P. D. (1995), "Television and Cultural Politics in Mexico: Some Notes on Televisa, the State, and Transnational Culture", en The Howard Journal of Communications, 6 (4), pp. 250-261.

Norris, P. y Pauling, B. (1999), "Local Content and Diversity: Television in Ten Countries", Nueva Zelanda, NZ on Air, en: www.nzonair.govt.nz/local_content99/exec/index.html.

Orozco, G. (1998), "México", en K.B. Jensen (ed.), News of the World: World Cultures Look at Television News, Londres, Nueva York, Routledge, pp. 126-143.

Press, A. L. (1991), Women Watching Television: Gender, Class, and Generation in the American Television Experience, Pennsylvania, University of Pennsylvania Press.

Sánchez Ruiz, E. (1996), "Flujos globales, nacionales y regionales de programación televisiva: el caso de México", en Comunicación y Sociedad, núm. 27, pp. 43-88.

"Séptima entrega de consumo cultural" (2001), en El Norte, disponible, el 3 de julio de 2001, en: www.elnorte.com.

Silverstone, R. (1996), Televisión y vida cotidiana, Buenos Aires, Amorrortu. TV Azteca (1999), disponible en: tvazteca.com.mx/inversionistas, diciembre. 
Varis, T. (1988), "Trends in International Television Flow", en C. Schneider y B. Wallis (eds.), en Global Television, EE.UU., The MIT, Press-Wedge Press, pp. 95-107.

Walker, A. J. (1996), "Couples Watching Television: Gender, Power, and the Remote Control", en Journal of Marriage and the Family, 58(4), pp. 813-823. 